\title{
The cys-loop ligand-gated ion channel gene superfamily of the nematode, Caenorhabditis elegans
}

\author{
Andrew K. Jones · David B. Sattelle
}

Received: 25 January 2008/ Accepted: 6 February 2008/Published online: 21 February 2008

(C) Springer-Verlag 2008

\begin{abstract}
The nematode, Caenorhabditis elegans, possesses the most extensive known superfamily of cys-loop ligand-gated ion channels (cys-loop LGICs) consisting of 102 subunit-encoding genes. Less than half of these genes have been functionally characterised which include cationpermeable channels gated by acetylcholine (ACh) and $\gamma$-aminobutyric acid (GABA) as well as anion-selective channels gated by ACh, GABA, glutamate and serotonin. Following the guidelines set for genetic nomenclature for C. elegans, we have designated unnamed subunits as $l g c$ genes (ligand-gated ion channels of the cys-loop superfamily). Phylogenetic analysis shows that several of these $l g c$ subunits form distinct groups which may represent novel cys-loop LGIC subtypes.
\end{abstract}

Keywords Caenorhabditis elegans . Ion channel . Acetylcholine · GABA · Glutamate $\cdot$ Serotonin

\section{Introduction}

Members of the cysteine-loop ligand-gated ion channel (cys-loop LGIC) superfamily are neurotransmitter receptors that mediate synaptic transmission in vertebrates and invertebrates. Cys-loop LGICs are made up of five homologous subunits arranged around a central ion channel (Sine and Engel 2006). The characteristic cys-loop motif is situated in the N-terminal extracellular ligand-binding region of each subunit and consists of two disulphide-bond forming cysteines separated by 13 amino acid residues,

A. K. Jones $(\bowtie) \cdot$ D. B. Sattelle

Department of Physiology, Anatomy and Genetics, University of Oxford, South Parks Road, Oxford OX1 3QX, UK e-mail: andrew.jones@dpag.ox.ac.uk several of which are highly conserved to form a signature sequence (Gene Ontology ID GO:0005230). The cys-loop plays roles in receptor assembly (Green and Wanamaker 1997) and gating of the ion channel (Grutter et al. 2005).

The subunit composition determines the functional and pharmacological properties of the cys-loop LGIC, thus receptor diversity is generated by multiple subunit-encoding genes. For instance, the human cys-loop LGIC superfamily consists of 45 genes encoding cation-permeable nicotinic acetylcholine receptors (nAChRs) (Kalamida et al. 2007), cation-permeable serotonin or 5-hydroxytryptamine type $3\left(5-\mathrm{HT}_{3}\right)$ receptors (Reeves and Lummis 2002), anion-permeable $\gamma$-aminobutyric acid (GABA) type A and $\mathrm{C}\left(\mathrm{GABA}_{\mathrm{A}}\right.$ and $\left.\mathrm{GABA}_{\mathrm{C}}\right)$ receptors (Bormann 2000; Darlison et al. 2005) and anion-permeable glycine receptors (Kirsch 2006). As demonstrated in the fruit fly (Drosophila melanogaster), honey bee (Apis mellifera) and red flour beetle (Tribolium castaneum), insect cys-loop LGIC superfamilies are more compact, consisting of just over 20 subunits (Jones and Sattelle 2006; Jones and Sattelle 2007; Littleton and Ganetzky 2000). Approximately 15 of these genes are known to encode cation-permeable nAChRs (Sattelle et al. 2005), anion and possibly cation channels gated by GABA (Buckingham et al. 2005), glutamate-gated anion channels (Vassilatis et al. 1997) and histamine-gated anion channels (Gisselmann et al. 2002; Zheng et al. 2002). The largest known cys-loop LGIC superfamily belongs to the simple nematode, Caenorhabditis elegans, where an early analysis of its completed genome revealed 90 ligand-gated ion channel genes (Bargmann 1998). In common with vertebrates, members of this large cys-loop LGIC superfamily include cationpermeable nAChRs (Jones and Sattelle 2004) and anionpermeable GABA receptors (Schuske et al. 2004). As is the case for insects, $C$. elegans has glutamate-gated anion 
channels (Wolstenholme and Rogers 2005) but so far no nematode histamine-gated ion channels have been found. However, C. elegans possesses cys-loop LGIC receptors not identified in vertebrates and insects which include anion channels gated by acetylcholine (Putrenko et al. 2005) and serotonin (Ranganathan et al. 2000). The considerable diversity of receptor subtypes in $C$. elegans may be broadened further as many cys-loop LGIC subunits have yet to be characterised. Here, we present an update on the genes present in the C. elegans cys-loop LGIC superfamily.

\section{Methods}

All C. elegans protein sequences bearing motifs particular to cys-loop LGICs were assembled from WormBase (http:// www.wormbase.org release WS185 Dec 23 2007). These motifs and their source databases are neurotransmitter-gated ion-channel ligand-binding INTERPRO:IPR006202, neurotransmitter-gated ion-channel INTERPRO:IPR006201, neurotransmitter-gated ion-channel ligand binding domain PFAM:PF02931, neurotransmitter-gated ion-channel transmembrane region PFAM:PF02932 and ligand-gated ion channel KOG3644. Cys-loop and TM2 sequences were identified from an alignment of protein sequences of whole subunits constructed with ClustalX (Thompson et al. 1997) using the slow-accurate mode with a gap opening penalty of 10 and a gap extension penalty of 0.1 as well as applying the Gonnet 250 protein weight matrix (Benner et al. 1994). The protein alignment was viewed using GeneDoc (http://www. nrbsc.org/gfx/genedoc/index.html). The neighbour-joining method (Saitou and Nei 1987), available with the ClustalX program, was used to construct a phylogenetic tree, which was then displayed using the TreeView application (Page 1996).

\section{Results and discussion}

Our analysis of the $C$. elegans genome revealed the largest cys-loop LGIC superfamily so far characterised consisting of 102 genes. As we have previously reported the C. elegans nAChR and orphan subunits (Brown et al. 2006; Jones et al. 2007; Jones and Sattelle 2004; Mongan et al. 1998), we concentrate here on the remaining cys-loop LGIC genes. For unnamed subunit genes, we continued to use the nomenclature first used for orphan $\mathrm{nAChR}$ subunits (Jones et al. 2007). Thus, 24 genes were designated $\operatorname{lgc}$ for ligand-gated ion channel of the cys-loop LGIC superfamily (Table 1). As shown in Fig. 1, the $C$. elegans cys-loop LGIC subunits were grouped according to sequence homology. As with the C. elegans nAChR subunits (Mongan et al. 1998), each group was named, if possible, after a well characterised subunit. For a detailed comparison of $C$. elegans cys-loop LGIC subunits with those of other organisms, see (Dent 2006).

Ungrouped subunits

Three subunits, LGC-32, LGC-33 and LGC-34, were not placed into any groups as they are highly divergent (Fig. 1), only showing up to 10,10 and $15 \%$ identity respectively with other $C$. elegans, human and D. melanogaster cys-loop LGICs. These subunits have not been functionally characterised so it is unknown what ligands act on them. The sequence of LGC-34 and a close homologue in the parasitic nematode, Dirofilaria immitis, has been previously described where it has been noted that even though the subunit possesses features common to cys-loop LGICs, such as conserved residues in the $\mathrm{N}$-terminal extracellular region and four transmembrane domains, the cys-loop is absent (Yates and Wolstenholme 2004). Interestingly, a bacterial protongated ion channel (Glvi) resembling cys-loop LGICs but also lacking the cys-loop has been recently reported (Bocquet et al. 2007; Tasneem et al. 2005). LGC-34 may thus represent more ancestral members of the cys-loop LGIC superfamily. Unlike Glvi, LGC-34 possesses two cysteine residues which are conserved in glutamate-, histamine- and vertebrate glycine-gated anion channels (Dent 2006; Yates and Wolstenholme 2004). Known as the second cys-loop, these two cysteines flank loop $\mathrm{C}$ which is a region that contributes to ligand binding (Corringer et al. 2000).

\section{The EXP-1 Group}

This group consists of only two subunits, one of which is EXP-1, a GABA-gated cation channel that mediates enteric muscle contraction (Beg and Jorgensen 2003). While EXP-1 overall resembles more closely anion permeable cys-loop LGICs such as UNC-49 as opposed to cation-permeable nAChRs, it lacks the PAR motif preceding the second transmembrane domain (TM2) which is important for anion selectivity (Jensen et al. 2005). Instead it possesses the residues ETE where the presence of glutamic acid residues has been implicated in determining cation selectivity (Jensen et al. 2005; Wotring and Weiss 2008). The other subunit in this group, LGC-35, also has a glutamate residue preceding TM2 (Table 1) and thus may be a cation channel.

\section{The AVR-14 Group}

This group consists of six subunits (Fig. 1) that make up glutamate-gated chloride channels that are targeted by the avermectin and milbemycin anthelmintics (Wolstenholme and Rogers 2005). Examples of $\mathrm{GluCl}$ function include AVR-15 and GLC-2 in the inhibition of pharyngeal 
Table 1 C. elegans cys-loop LGIC subunits that have been given names in this report. Amino acid residues preceding TM2 that are important for determining the charge selectivity of the ion channel (Jensen et al. 2005) are given.

The cys-loop sequence is shown with the cysteine residues highlighted in black shading while gray shading indicates conserved residues. The presence of a putative second cys-loop (Dent 2006) is also noted

\begin{tabular}{|c|c|c|c|c|c|}
\hline $\begin{array}{l}\text { CGC } \\
\text { name }\end{array}$ & $\begin{array}{l}\text { Sequence } \\
\text { name }\end{array}$ & Group & $\begin{array}{l}\text { Amino acids } \\
\text { before TM2 }\end{array}$ & Cys-loop sequence & $\begin{array}{l}\text { Second cys-loop } \\
\text { present? }\end{array}$ \\
\hline LGC-32 & T19D7.1 & - & TRC & CKEQSDSHPFSNNTC & \\
\hline LGC-33 & Y55F3BR.4 & - & LMD & COTNAWKYPFESFTC & \\
\hline LGC-34 & T27A1.4 & - & VPR & AYGTMFPETNSRQFT & second cys-loop \\
\hline LGC-35 & Y46G5A.26 & EXP-1 & ETS & CGMDLTLPFDTQLC & \\
\hline LGC-36 & F07B10.5 & UNC-49 & AER & COMDMSRYPLDKQAC & \\
\hline LGC-37 & ZC482.5 & UNC-49 & PAR & CQMFLKKEPMDTQAC & \\
\hline LGC-38 & F11H8.2 & UNC-49 & QAR & CPMSZHTEPLDRQEC & \\
\hline LGC-39 & F09G2.5 & GGR-1 & PAR & CMMDLKLFPDYQEC & second cys-loop \\
\hline LGC-40 & T24D8.1 & GGR-1 & PAR & CNMDIWKYPLDSQE & second cys-loop \\
\hline LGC-41 & C39B10.2 & GGR-1 & PAR & CSLNLRYYPMDQQLC & second cys-loop \\
\hline LGC-42 & Y39A3B.2 & GGR-1 & PAR & CNLDLKDYPLDYQTC & second cys-loop \\
\hline LGC-43 & C43F9.9 & LGC-45 & DVR & CFMSFCLYPHDRQEC & second cys-loop \\
\hline LGC-44 & F46F3.2 & LGC-45 & EGR & AQIVICKYPHDNPAV & second cys-loop \\
\hline LGC-45 & W10G11.16 & LGC-45 & EGR & CNLILCKYPHDKQTC & second cys-loop \\
\hline LGC-46 & Y71D11A.5 & ACC-1 & PAR & CIMDITKFFDNVTC & \\
\hline LGC-47 & F47A4.1 & ACC-1 & PAR & CVMDLTKEPMDSIEC & \\
\hline LGC-48 & C50B6.11 & ACC-1 & TPR & CNMDIVDFPMDTQSC & \\
\hline LGC-49 & K10D6.1 & ACC-1 & PAR & CDISIELFPLIQEC & \\
\hline LGC-50 & T20B12.9 & MOD-1 & SAR & CSVNLKMEPFDSLSC & \\
\hline LGC-51 & F12B6.3 & GGR-3 & PAR & CSMDIARFPIDTQYC & \\
\hline LGC-52 & Y73F8A.2 & GGR-3 & PAR & CQMNZRNFPLDSIRC & \\
\hline LGC-53 & $\mathrm{T} 21 \mathrm{~F} 2.1$ & GGR-3 & PAR & CKLDITYFPMDRQSC & \\
\hline LGC-54 & T15B7.16 & GGR-3 & PAR & CMVDIVLFMDIMNC & \\
\hline LGC-55 & Y113G7A.5 & GGR-3 & PAR & CEMDFSFFMDRVMC & \\
\hline
\end{tabular}

pumping (Dent et al. 1997; Laughton et al. 1997; Pemberton et al. 2001) and AVR-14, AVR-15, GLC-1 and GLC-3 in regulating locomotion (Cook et al. 2006). Recently, it has been shown GLC-3 plays a role in olfactory behaviour (Chalasani et al. 2007).

\section{The UNC-49 Group}

Products of the unc-49 gene form a GABA-gated anion channel that mediates body muscle inhibition during locomotion (Bamber et al. 1999; Richmond and Jorgensen 1999). There are four other subunits included in this group (Fig. 1).
With regard to other species, members of the UNC-49 group are clearly most closely related to mammalian and insect GABA-gated anion channels (Dent 2006). GAB-1 forms functional GABA receptors when coexpressed in Xenopus laevis oocytes with either HG1A or HG1E, which are putative GABA receptor subunits from the parasitic nematode Haemonchus contortus (Feng et al. 2002). The remaining subunits have yet to be characterised but it is worth noting that LGC-36 possesses the amino acids AER instead of PAR before TM2 (Table 1). The presence of a glutamic acid residue at this position and the absence of a proline may result in a cation-selective channel (Jensen et al. 2005). 
Fig. 1 Tree showing the cysloop LGIC gene superfamily of C. elegans. This figure focuses on cys-loop LGIC subunits other than nAChRs although representative subunits of the nAChR groups are shown. For the complete $C$. elegans nAChR gene family, see (Jones et al. 2007). Based on protein sequence homology, the subunits are divided into eight groups with three highly divergent subunits, LGC-32, LGC-33 and LGC-34, not belonging to any group

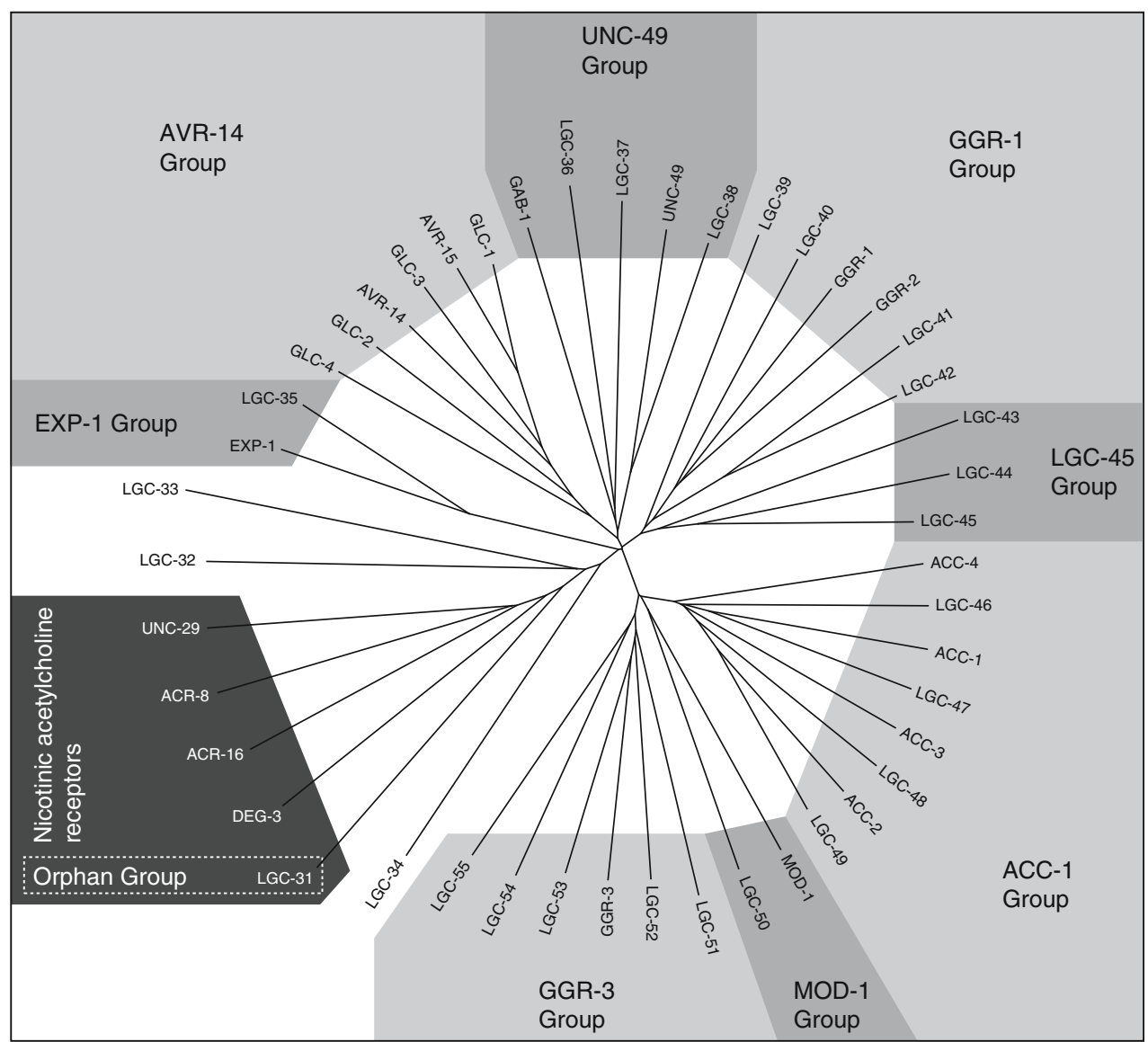

The LGC-45 Group

\section{The GGR-1 Group}

This group includes six subunits (Fig. 1), the functional characterisation of which has so far not been published. The neurotransmitters/ligands to which GGR-1 group subunits respond to cannot be easily inferred through phylogenetic analysis. For example, when comparing with human cys-loop LGICs they bear closest resemblance to glycine $\alpha$ subunits with approximately $25 \%$ identity while LGC-42 is slightly more similar to histamine-gated anion channels with $26 \%$ identity when comparing with insect cys-loop LGICs. Members of the GGR-1 group have been previously denoted as "ce_Group I" subunits which most closely resemble insect histamine-gated anion channels (Dent 2006). It would be of interest to determine if members of the GGR-1 group respond to glycine, histamine or other ligands not so far known to act on $C$. elegans cysloop LGICs. The subunits of the GGR-1 group are likely to be anion-selective as they all possess the PAR motif before TM2 (Table 1) which is important for anion selectivity (Jensen et al. 2005). The only exception is GGR-1 which instead has the amino acid residues PGR. With the proline still present and an absence of an acidic residue (particularly glutamic acid) in this region, it is likely that GGR-1 will also be anion selective.
This group consists of three subunits (Fig. 1), the functional characterisation of which has so far not been published. As is the case for members of the GGR-1 group, LGC-43, LGC-44 and LGC-45 most closely resemble glycine $\alpha$ subunits and histamine-gated anion channels when compared with human and insect cys-loop LGICs respectively. However, unlike the GGR-1 group, the LGC-45 group subunits are likely to be cation selective as they lack the PAR motif before TM2 (Table 1) which is important for anion selectivity (Jensen et al. 2005). In particular, LGC-44 and LGC-45 possess glutamic acid instead of the proline residue which is likely to result in a cation-selective channel (Wotring and Weiss 2008). While LGC-44 shows notable sequence identity with other cys-loop LGIC subunits (up to $37 \%$ with LGC-45), it lacks the cys-loop (Table 1), thus it may represent an ancestral cys-loop LGIC subunit as has been noted for LGC-34.

\section{The ACC-1 Group}

This group includes ACC-1, ACC-2, ACC-3 and ACC-4 which are acetylcholine-gated anion channels (Putrenko 
et al. 2005). Acetylcholine-gated anion channels have also been characterised from the snail, Lymnae stagnalis, which appear to have evolved from cation channels through amino acid substitutions in the ion channel pore (van Nierop et al. 2005). In contrast, acetylcholine-gated anion channels of the ACC-1 group may have arisen from substitutions in the ligand-binding domain of anion channels (Putrenko et al. 2005; van Nierop et al. 2005).

\section{The MOD-1 Group}

MOD-1 modulates locomotory behaviour and is the only known invertebrate cys-loop LGIC to be gated by serotonin (Ranganathan et al. 2000). Unlike mammals which possess cation-permeable serotonin receptors (Reeves and Lummis 2002), MOD-1 is anion selective. One other subunit, LGC50 , is closely related to MOD-1 (Fig. 1).

\section{The GGR-3 Group}

This group includes six subunits (Fig. 1), the functional characterisation of which has so far not been published. All six subunits are likely to form anion-selective channels as they have the PAR amino acid motif before TM2 (Table 1) (Jensen et al. 2005). When comparing with human cys-loop LGICs they bear closest resemblance to GABA $\alpha, \gamma$ and $\varepsilon$ subunits with approximately $22 \%$ identity while they most closely resemble histamine-gated chloride channels $(21 \%$ identity) when comparing with insect cys-loop LGICs. As with the GGR-1 group, it would be of interest to determine if the GGR-3 group consists of ion channels responding to ligands not so far known to act on $C$. elegans cys-loop LGICs.

Cys-loop LGIC superfamilies of other nematode species

Genome sequencing projects are allowing the comparison of cys-loop LGIC superfamilies from different nematode species. For instance, Caenorhabditis briggsae, which is seemingly identical to C. elegans (Gupta et al. 2007; Stein et al. 2003), also has an extensive cys-loop LGIC gene superfamily although there are a few exceptions where there appears to be gene expansions in C. elegans, mainly within the nAChR orphan group. For example, $l_{g c-23,} l_{c}-24$ and $l_{g c-28}$ in C. elegans (Jones et al. 2007) may be paralogues resulting from gene duplication in the elegans species lineage since only one homologue $(\mathrm{Cbr}$ $l g c-28)$ is observed in C. briggsae. In line with this, $l g c-$ 23 and $l g c-24$ are situated close together within $6 \mathrm{~kb}$ in the $C$. elegans genome which may reflect a recent gene duplication event. Likewise, $\lg c-11$ and $l g c-12$, as well as $\lg c-25$ and $l g c-26$ have single homologues in C. briggsae,
Cbr-lgc-11 and $C b r-\lg c-26$ respectively. Six C. elegans cys-loop LGIC subunits, $l g c-13$ to $l g c-18$, are tightly clustered within $20 \mathrm{~kb}$ of the T01H10 cosmid whereas in C. briggsae there are seven similar genes (CBG01219, CBG01221, CBG02706, CBG16212, CBG16226, CBG16227 and CBG16229), all of which are not clustered together. Outside of the nAChR orphan group, avr15 and glc- 1 may be paralogues arising in the elegans lineage as there is only a single homologue (CBG06688) in C. briggsae.

The cys-loop LGIC gene families of the parasitic nematodes, Brugia malyai and Trichinella spiralis, are much smaller than those of $C$. elegans and C. briggsae consisting of 30 and 19 subunits respectively (Williamson et al. 2007). The cys-loop LGIC subunits of both parasites have clear orthologous relationships with those of $C$. elegans with one exception, a nAChR subunit (ACR-26) which so far appears particular to B. malayi. As discussed by Williamson and colleagues, the striking difference in the cysloop LGIC gene family sizes may reflect a free-living versus a parasitic lifestyle. Thus, the large complement of subunits in C. elegans and C. briggsae may be required for a small nervous system to be able to respond to many environmental cues which may be more restricted in the specific environmental niche occupied by parasitic nematodes. This shows that the extensive cys-loop LGIC gene superfamily observed for C. elegans is not a feature of all nematodes.

Acknowledgments The authors would like to thank Jonathan Hodgkin for approving the novel nomenclature used in this report.

\section{References}

Bamber BA, Beg AA, Twyman RE, Jorgensen EM (1999) The Caenorhabditis elegans unc-49 locus encodes multiple subunits of a heteromultimeric GABA receptor. J Neurosci 19:5348-5359

Bargmann CI (1998) Neurobiology of the Caenorhabditis elegans genome. Science 282:2028-2033

Beg AA, Jorgensen EM (2003) EXP-1 is an excitatory GABA-gated cation channel. Nat Neurosci 6:1145-1152

Benner SA, Cohen MA, Gonnet GH (1994) Amino acid substitution during functionally constrained divergent evolution of protein sequences. Protein Eng 7:1323-1332

Bocquet N, Prado de Carvalho L, Cartaud J, Neyton J, Le Poupon C, Taly A, Grutter T, Changeux JP, Corringer PJ (2007) A prokaryotic proton-gated ion channel from the nicotinic acetylcholine receptor family. Nature 445:116-119

Bormann J (2000) The 'ABC' of GABA receptors. Trends Pharmacol Sci 21:16-19

Brown LA, Jones AK, Buckingham SD, Mee CJ, Sattelle DB (2006) Contributions from Caenorhabditis elegans functional genetics to antiparasitic drug target identification and validation: nicotinic acetylcholine receptors, a case study. Int J Parasitol 36:617-624

Buckingham SD, Biggin PC, Sattelle BM, Brown LA, Sattelle DB (2005) Insect GABA receptors: splicing, editing, and targeting by antiparasitics and insecticides. Mol Pharmacol 68:942-951 
Chalasani SH, Chronis N, Tsunozaki M, Gray JM, Ramot D, Goodman MB, Bargmann CI (2007) Dissecting a circuit for olfactory behaviour in Caenorhabditis elegans. Nature 450:63-70

Cook A, Aptel N, Portillo V, Siney E, Sihota R, Holden-Dye L, Wolstenholme A (2006) Caenorhabditis elegans ivermectin receptors regulate locomotor behaviour and are functional orthologues of Haemonchus contortus receptors. Mol Biochem Parasitol 147:118-125

Corringer PJ, Le Novere N, Changeux JP (2000) Nicotinic receptors at the amino acid level. Annu Rev Pharmacol Toxicol 40:431458

Darlison MG, Pahal I, Thode C (2005) Consequences of the evolution of the $\operatorname{GABA}(\mathrm{A})$ receptor gene family. Cell Mol Neurobiol 25:607-624

Dent JA (2006) Evidence for a diverse cys-loop ligand-gated ion channel superfamily in early bilateria. J Mol Evol 62:523-535

Dent JA, Davis MW, Avery L (1997) avr-15 encodes a chloride channel subunit that mediates inhibitory glutamatergic neurotransmission and ivermectin sensitivity in Caenorhabditis elegans. EMBO J 16:5867-5879

Feng XP, Hayashi J, Beech RN, Prichard RK (2002) Study of the nematode putative GABA type-A receptor subunits: evidence for modulation by ivermectin. J Neurochem 83:870-878

Gisselmann G, Pusch H, Hovemann BT, Hatt H (2002) Two cDNAs coding for histamine-gated ion channels in D. melanogaster. Nat Neurosci 5:11-12

Green WN, Wanamaker CP (1997) The role of the cystine loop in acetylcholine receptor assembly. J Biol Chem 272:2094520953

Grutter T, de Carvalho LP, Dufresne V, Taly A, Edelstein SJ, Changeux JP (2005) Molecular tuning of fast gating in pentameric ligand-gated ion channels. Proc Natl Acad Sci U S A $102: 18207-18212$

Gupta BP, Johnsen R, Chen N (2007) Genomics and biology of the nematode Caenorhabditis briggsae. WormBook 1-16

Jensen ML, Schousboe A, Ahring PK (2005) Charge selectivity of the Cys-loop family of ligand-gated ion channels. J Neurochem 92:217-225

Jones AK, Davis P, Hodgkin J, Sattelle DB (2007) The nicotinic acetylcholine receptor gene family of the nematode Caenorhabditis elegans: an update on nomenclature. Invert Neurosci 7:129_ 131

Jones AK, Sattelle DB (2004) Functional genomics of the nicotinic acetylcholine receptor gene family of the nematode, Caenorhabditis elegans. Bioessays 26:39-49

Jones AK, Sattelle DB (2006) The cys-loop ligand-gated ion channel superfamily of the honeybee, Apis mellifera. Invert Neurosci 6:123-132

Jones AK, Sattelle DB (2007) The cys-loop ligand-gated ion channel gene superfamily of the red flour beetle, Tribolium castaneum. BMC Genomics 8:327

Kalamida D, Poulas K, Avramopoulou V, Fostieri E, Lagoumintzis G, Lazaridis K, Sideri A, Zouridakis M, Tzartos SJ (2007) Muscle and neuronal nicotinic acetylcholine receptors. Structure, function and pathogenicity. FEBS J 274:3799-3845

Kirsch J (2006) Glycinergic transmission. Cell Tissue Res 326:535540

Laughton DL, Lunt GG, Wolstenholme AJ (1997) Reporter gene constructs suggest that the Caenorhabditis elegans avermectin receptor beta-subunit is expressed solely in the pharynx. J Exp Biol 200:1509-1514

Littleton JT, Ganetzky B (2000) Ion channels and synaptic organization: analysis of the Drosophila genome. Neuron 26:35-43

Mongan NP, Baylis HA, Adcock C, Smith GR, Sansom MS, Sattelle DB (1998) An extensive and diverse gene family of nicotinic acetylcholine receptor alpha subunits in Caenorhabditis elegans. Recept Channels 6:213-228

Page RD (1996) TreeView: an application to display phylogenetic trees on personal computers. Comput Appl Biosci 12:357-358

Pemberton DJ, Franks CJ, Walker RJ, Holden-Dye L (2001) Characterization of glutamate-gated chloride channels in the pharynx of wild-type and mutant Caenorhabditis elegans delineates the role of the subunit GluCl-alpha2 in the function of the native receptor. Mol Pharmacol 59:1037-1043

Putrenko I, Zakikhani M, Dent JA (2005) A family of acetylcholinegated chloride channel subunits in Caenorhabditis elegans. J Biol Chem 280:6392-6398

Ranganathan R, Cannon SC, Horvitz HR (2000) MOD-1 is a serotonin-gated chloride channel that modulates locomotory behaviour in C. elegans. Nature 408:470-475

Reeves DC, Lummis SC (2002) The molecular basis of the structure and function of the 5-HT3 receptor: a model ligand-gated ion channel (review). Mol Membr Biol 19:11-26

Richmond JE, Jorgensen EM (1999) One GABA and two acetylcholine receptors function at the $C$. elegans neuromuscular junction. Nat Neurosci 2:791-797

Saitou N, Nei M (1987) The neighbor-joining method: a new method for reconstructing phylogenetic trees. Mol Biol Evol 4:406-425

Sattelle DB, Jones AK, Sattelle BM, Matsuda K, Reenan R, Biggin PC (2005) Edit, cut and paste in the nicotinic acetylcholine receptor gene family of Drosophila melanogaster. Bioessays 27:366-376

Schuske K, Beg AA, Jorgensen EM (2004) The GABA nervous system in C. elegans. Trends Neurosci 27:407-414

Sine SM, Engel AG (2006) Recent advances in Cys-loop receptor structure and function. Nature 440:448-455

Stein LD, Bao Z, Blasiar D, Blumenthal T, Brent MR, Chen N, Chinwalla A, Clarke L, Clee C, Coghlan A, Coulson A, D'Eustachio P, Fitch DH, Fulton LA, Fulton RE, Griffiths-Jones S, Harris TW, Hillier LW, Kamath R, Kuwabara PE, Mardis ER, Marra MA, Miner TL, Minx P, Mullikin JC, Plumb RW, Rogers J, Schein JE, Sohrmann M, Spieth J, Stajich JE, Wei C, Willey D, Wilson RK, Durbin R, Waterston RH (2003) The genome sequence of Caenorhabditis briggsae: a platform for comparative genomics. PLoS Biol 1:E45

Tasneem A, Iyer LM, Jakobsson E, Aravind L (2005) Identification of the prokaryotic ligand-gated ion channels and their implications for the mechanisms and origins of animal Cys-loop ion channels. Genome Biol 6:R4

Thompson JD, Gibson TJ, Plewniak F, Jeanmougin F, Higgins DG (1997) The CLUSTAL_X windows interface: flexible strategies for multiple sequence alignment aided by quality analysis tools. Nucleic Acids Res 25:4876-4882

van Nierop P, Keramidas A, Bertrand S, van Minnen J, Gouwenberg Y, Bertrand D, Smit AB (2005) Identification of molluscan nicotinic acetylcholine receptor (nAChR) subunits involved in formation of cation- and anion-selective nAChRs. J Neurosci 25:10617-10626

Vassilatis DK, Elliston KO, Paress PS, Hamelin M, Arena JP, Schaeffer JM, Van der Ploeg LH, Cully DF (1997) Evolutionary relationship of the ligand-gated ion channels and the avermectinsensitive, glutamate-gated chloride channels. J Mol Evol 44:501-508

Williamson SM, Walsh TK, Wolstenholme AJ (2007) The cys-loop ligand-gated ion channel gene family of Brugia malayi and Trichinella spiralis: a comparison with Caenorhabditis elegans. Invert Neurosci 7:219-226

Wolstenholme AJ, Rogers AT (2005) Glutamate-gated chloride channels and the mode of action of the avermectin/milbemycin anthelmintics. Parasitology 131(Suppl):S85-95 
Wotring VE, Weiss DS (2008) Charge scan reveals an extended region at the intracellular end of the GABA receptor pore that can influence ion selectivity. J Gen Physiol 131:87-97

Yates DM, Wolstenholme AJ (2004) Dirofilaria immitis: identification of a novel ligand-gated ion channel-related polypeptide. Exp Parasitol 108:182-185
Zheng Y, Hirschberg B, Yuan J, Wang AP, Hunt DC, Ludmerer SW, Schmatz DM, Cully DF (2002) Identification of two novel Drosophila melanogaster histamine-gated chloride channel subunits expressed in the eye. J Biol Chem 277:2000-2005 